\title{
Mental health, behaviour and intellectual abilities of people with Down syndrome
}

\author{
Tuomo Määttä ${ }^{1}$, Tuula Tervo-Määttä ${ }^{2}$, Anja Taanila ${ }^{3}$, Markus Kaski ${ }^{4}$ \\ and Matti livanainen ${ }^{4}$ \\ ${ }^{1}$ Service Centre of Kuusanmäki, ${ }^{2}$ Department of Teacher Education, University of Oulu, \\ ${ }^{3}$ Department of Public Health Science and General Practice, University of Oulu, \\ ${ }^{4}$ Rinnekoti Research Centre and Department of Child Neurology, University of Helsinki, Finland
}

\begin{abstract}
The mental health, adaptive behaviour and intellectual abilities of people with Down syndrome $(n=129)$ were evaluated in a population-based survey of social and health care records. Females had better cognitive abilities and speech production compared with males. Males had more behavioural problems than females. Behaviour suggestive of attention deficit hyperactivity disorder was often seen in childhood. Depression was diagnosed mainly in adults with mild to moderate intellectual disability. Autistic behaviour was most common in individuals with profound intellectual disability. Elderly people often showed decline of adaptive behaviour associated with Alzheimer's disease. Case descriptions are presented to illustrate the multitude of mental health and behavioural issues seen from childhood to old age in this population.
\end{abstract}

Keywords: Down syndrome, adaptive behaviour, mental health, gender, survey, case records

\section{Introduction}

Individuals with Down syndrome have

- delay in cognitive development with specific deficits in speech, language production and auditory shortterm memory

- fewer adaptive behaviour problems than individuals with other cognitive disabilities

- increased risk for depression and Alzheimer's disease (Chapman \& Hesketh, 2000).

People with Down syndrome show marked individual differences in cognitive abilities and skills. Both genetic and environmental effects contribute to these differences. High level of maternal education correlates with higher developmental scores in home-reared children with Down syndrome (Sharav et al., 1985). Adult females with Down syndrome score higher than males (Nagumo, 1994). The mean age of starting to walk is delayed by six months or more in the group with low compared with high intelligence quotient (Nagumo, 1994). Libb et al., (1983) reported that the adaptive behaviour scores of children with Down syndrome born to older parents were significantly lower than the scores of Down children born to younger parents. Age modifies health, skills and behaviour. The functions of the central nervous system are of critical importance for the processes of learning and development. Learning and acquisition of skills in youth may be followed by a gradual loss of abilities in later life.

Although children with Down syndrome are at lower risk for psychopathology than others with intellectual 
disability (Haveman et al., 1994), they do show more problems than typically developing children (Dykens et al., 2002). Older adolescents with Down syndrome show fewer externalising symptoms and a subtle increase in withdrawal compared with younger ones (Dykens et al., 2002). Myers and Pueschel (1991) found a 22 percent frequency of psychiatric disorders in people with Down syndrome. Disruptive behaviours, anxiety disorders and repetitive behaviours were common in those aged under 20 years, as was depression in young adults and dementia in elderly people. Compulsive-like behaviour (including ritualistic habits and perfectionistic behaviours) was more frequent and conspicuous in children with Down syndrome compared with mental age-matched controls, suggesting that some repetitive behaviours may belong to the behavioural phenotype of individuals with Down syndrome (Evans \& Gray, 2000). Childhood disorder in individuals with Down syndrome has a good early prognosis with little evidence of persistence into adult life (McCarthy \& Boyd, 2001).

Collacott et al. (1992) compared adults with Down syndrome and adults with intellectual disabilities due to other aetiologies. The same proportion of each group had been given a diagnosis of autism. People with Down syndrome were more likely to have been diagnosed as having depression and dementia, while controls were more likely to have been diagnosed as suffering from conduct disorder, personality disorder or schizophrenia/ paranoid state.

Depression in people with Down syndrome is rarely verbalised and commonly appears as crying, depressed appearance or mood lability. Vegetative symptoms of disinterest with severe withdrawal and mutism, psychomotor retardation, decreased appetite, weight loss and insomnia are prominent. Verbal expression of preoccupation with suicide, death, self-depreciation and guilt is infrequent. Hallucinations may be prominent. This pattern of vegetative symptomatology with few verbal complaints and prominent hallucinations may be related to moderate intellectual disability rather than specifically to Down syndrome (Myers \& Pueschel, 1995).

Elderly people with Down syndrome have fewer mental health problems than other people with intellectual disabilities. High psychological problem scores correspond with medical diagnoses of dementia (Haveman et al., 1994). Collacott et al., (1998) compared the behavioural profiles of adults with Down syndrome and adults with intellectual disabilities of other aetiologies. Despite equal age and developmental quotient, the Down syndrome group were less likely to demonstrate maladaptive behaviours. Depression and indifference, as well as subsequent problems in language functioning, are associated with neurological changes (brain atrophy in MRI and presence of pathological reflexes in physical neurological examination) in adults with Down syndrome.
The primary emotional change is a decline in social discourse, e.g., conversational style, literal understanding and verbal expression in social contexts, while problems of poor pragmatic language functioning appear later in the course of suspected Alzheimer's disease (Nelson et al., 2001).

Cooper and Prasher (1998) compared the behavioural symptoms of dementia in a group with Down syndrome and a group with intellectual disability due to other causes. The group with Down syndrome had a higher prevalence of low mood, restlessness or hyperactivity, disturbed sleep, excessive uncooperativeness and auditory hallucinations. Aggression occurred with greater frequency in the subjects with intellectual disability due to other causes. Cosgrave et al., (1999) reported that the presence of dementia is not predictive of aggression or maladaptive behaviour. However, the level of adaptive behaviour is lower in subjects with dementia.

The aim of this paper is to review mental health and adaptive behaviour in people with Down syndrome and to correlate behaviour and mental health with intellectual abilities and gender. The results of a population-based survey of records and case descriptions are presented

\section{Method}

The social and health service records of all identified persons with Down syndrome in a population of about 90,000 were surveyed. The case records of people with Down syndrome $(n=129)$ in the Specialised Service Register in Kainuu were identified and analysed. The records contained repeated psychological, educational, medical and social evaluations from 1970 to 2004 at ages of 0 66.7 years. The mean age at the last visit of the 53 females was 35 years and that of the 76 males 29 years. (Table 1.)

The ethics committee of Kainuu Hospital District approved the study plan. The Finnish Ministry of Social Affairs and Health gave permission for the linkage of social and health register data needed in the study.

Behavioural and mental health problems were separately scored for severity from 0 (no problems) to 4 (very severe problems with major difficulties to manage) as follows. Mental health (mood, anxiety): no problems 0 , mild depression or withdrawal 1, moderate depression, anxiety or fears 2 , severe depression, anxiety, somatic symptoms 3 , very severe depression, psychotic symptoms or severe

\section{Table 1. Characteristics of the study population} $(n=129)$

\begin{tabular}{llcc}
\hline & & Males $(\mathrm{n}=76)$ & Females $(\mathrm{n}=53)$ \\
\hline Birth year & range & $1933-2002$ & $1933-2003$ \\
Age at last visit & range (mean) & $0-60.8(29)$ & $0-66.7(35)$ \\
\hline
\end{tabular}


T. Määttä et al. • Mental health, behaviour and intellectual abilities of people with Down syndrome

self-injury 4. Behaviour: no problems 0 , occasional difficulties 1 , occasional aggressive outbursts, destruction of material objects 2 , severe irritability, disturbing behaviour, attacking others 3 , difficult to manage, dangerous to others 4 .

Intellectual disability had been determined by repeated psychological assessments based on the diagnostic criteria of the International Classification of Diseases and Related Health Problems (ICD-10, World Health Organisation, 1992). The ICD-10 criteria for intellectual disability include adaptive behaviour in addition to cognitive abilities. The severity of intellectual disability was scored from 1 to 4 according to the best level achieved by each individual as follows: mild (IQ 50-69) 1, moderate (IQ 35-49) 2, severe (IQ 20-34) 3, profound intellectual disability $(\mathrm{IQ}<20) 4$.

The data was analysed using the Microsoft Excel and SPSS 11.5 for Windows software packages. Descriptive statistics, cross-tabulations with Chi-square test $\left(\mathrm{Chi}^{2}\right.$ test) for statistical significance and non-parametric correlation (Spearman) and partial correlation to control for age effects were used.

\section{Results}

The data available in the social and medical records varied greatly over the more than thirty-year period surveyed. Carefully recorded repeated professional social, psychological and medical evaluations were available for most persons.

Intellectual disability was mild in $23(19 \%)$, moderate in $36(30 \%)$, severe in $40(33 \%)$ and profound in $22(18 \%)$ persons evaluated $(n=121)$. The degree of intellectual disability remained undetermined in the remaining 8 persons. Children and adolescents had mild intellectual disability more often compared with adults. People evaluated under the age of 20 years had mild or moderate intellectual disability more often $(71 \%)$ than those evaluated at the age of 20 to 39 years (44\%) or after the age of 40 years $(33 \%)$.

Women had better cognitive abilities than men $(p=0.05)$. Fifty-three percent of women had mild or moderate intellectual disability compared with $46 \%$ of men. Profound intellectual disability was seen in $10 \%$ of women and in $24 \%$ of men. (Table 2.)

Almost $80 \%$ of those evaluated after early childhood produced speech: single spoken words $(35 \%)$ or at least short sentences (44\%). Speech production was statistically significantly better in women compared with men $(p<0.05)$. No differences in speech were seen between the age groups. (Table 3.)

Mental health (depression/anxiety) and behaviour based on recorded data could be scored for 108 persons $(83.7 \%$ out of the total of 129 persons). For 48 persons (44\% of

\begin{tabular}{lcccccc}
\hline \multicolumn{3}{c}{ Table 2. Intellectual disability by gender $(\mathbf{n}=121)$} \\
\hline & \multicolumn{2}{c}{ Males } & \multicolumn{2}{c}{ Females } & \multicolumn{2}{c}{ Total } \\
& count & $\%$ & count & $\%$ & count & $\%$ \\
\hline mild & 9 & 12.9 & 14 & 27.5 & 23 & 19.0 \\
moderate & 23 & 32.9 & 13 & 25.5 & 36 & 29.8 \\
severe & 21 & 30.0 & 19 & 37.3 & 40 & 33.1 \\
profound & 17 & 24.3 & 5 & 9.8 & 22 & 18.2 \\
\hline
\end{tabular}

\section{Chi-Square Tests}

Pearson Chi-Square 7.717, df 3, Asymp. Sig. (2-sided) .052

Likelihood Ratio 7.931, df 3, Asymp. Sig. (2-sided) 047

Linear-by-Linear Association 3.880, df 1, Asymp. Sig. (2-sided) .049

Table 3. Speech production by gender $(n=115)$

\begin{tabular}{lcccccc}
\hline & \multicolumn{2}{c}{ Males } & \multicolumn{2}{c}{ Females } & \multicolumn{2}{c}{ Total } \\
& count & $\%$ & count & $\%$ & count & $\%$ \\
\hline no words & 18 & 26.5 & 7 & 14.9 & 25 & 21.7 \\
single words & 27 & 39.7 & 13 & 27.7 & 40 & 34.8 \\
sentences & 23 & 33.8 & 27 & 57.4 & 50 & 43.5 \\
\hline
\end{tabular}

\section{Chi-Square Tests}

Pearson Chi-Square 6.440, df 2, Asymp. Sig. (2-sided) .040

Likelihood Ratio 6.479, df 2, Asymp. Sig. (2-sided) 039

Linear-by-Linear Association 5.643, df 1, Asymp. Sig. (2-sided) .018

the 108 evaluated) no problems related to behaviour had been recorded, while 36 (33\%) had experienced occasional difficulties, 10 (9\%) had exhibited occasional aggressive outbursts and destroyed material objects, another 10 (9\%) had shown severe irritability and disturbing behaviour and physically attacked others, and 4 (4\%) had been difficult to manage or even dangerous to others.

Severe behavioural problems were statistically significantly more common among males compared with females $(p<0.05)$ (Table 4.).

For 66 persons ( $61 \%$ of the 108 evaluated) no problems related to mood or anxiety had been recorded, whereas 18 (17\%) had experienced mild depression/withdrawal, 12 (11\%) moderate depression, anxiety or fears, 9 (8\%) severe depression, anxiety and somatic symptoms, and 3 (3\%) severe depression, psychotic symptoms or severe self-injury. No differences in mental health were seen between males and females.

Eleven of the 33 patients (33\%) with repeated psychological evaluations during childhood had behaviour suggestive of attention deficit hyperactivity disorder. None were treated with stimulants. Depression had been identified and treated mainly in people with mild to moderate disability. Severe self-injurious behaviour and aggressive behaviour were sometimes very difficult to treat. Autis- 


\begin{tabular}{lccccccc}
\hline \multicolumn{7}{l}{ Table 4. Behaviour by gender $(\mathbf{n}=108)$} \\
\hline Behaviour & \multicolumn{2}{c}{ Males } & \multicolumn{2}{c}{ Females } & \multicolumn{2}{c}{ Total } \\
& count & $\%$ & count & $\%$ & count & $\%$ \\
\hline no problems & 28 & 45.9 & 20 & 42.6 & 48 & 44.4 \\
$\begin{array}{l}\text { occasional } \\
\text { problems }\end{array}$ & 15 & 24.6 & 21 & 44.7 & 36 & 33.3 \\
$\begin{array}{l}\text { severe } \\
\text { problems }\end{array}$ & 18 & 29.5 & 6 & 12.8 & 24 & 22.2 \\
\hline
\end{tabular}

Chi-Square Tests

Pearson Chi-Square 6.630, df 2 Asymp. Sig. (2-sided) .036

Likelihood Ratio 6.803, df 2, Asymp. Sig. (2-sided) .033

Linear-by-Linear Association .764, df 1, Asymp. Sig. (2-sided) .382

\begin{tabular}{|c|c|c|c|}
\hline & $\begin{array}{l}\text { Intellectual } \\
\text { disability }\end{array}$ & $\begin{array}{l}\text { Speech } \\
\text { impairment }\end{array}$ & Age at last visit \\
\hline $\begin{array}{l}\text { Intellectual } \\
\text { disability }\end{array}$ & 1.000 & $.659(* *)$ & $.428(* *)$ \\
\hline $\begin{array}{l}\text { Speech } \\
\text { impairment }\end{array}$ & $.659\left(^{* *}\right)$ & 1.000 & .014 \\
\hline $\begin{array}{l}\text { Behavioural } \\
\text { problems }\end{array}$ & .026 & -.041 & -.039 \\
\hline $\begin{array}{l}\text { Depression, } \\
\text { anxiety }\end{array}$ & -.115 & $-.231\left(^{* *}\right)$ & -.112 \\
\hline Age at last visit & $.428\left(^{* *}\right)$ & .014 & 1.000 \\
\hline
\end{tabular}

** Correlation is significant at the 0.01 level (1-tailed)

Table 6. Partial correlation coefficients (controlling for age at last visit and birth year)

\begin{tabular}{lcc}
\hline & $\begin{array}{c}\text { Intellectual } \\
\text { disability }\end{array}$ & Speech impairment \\
\hline Intellectual disability & 1.000 & $\left..702^{* *}\right)$ \\
Speech impairment & $.702^{(*)}$ & 1.000 \\
Behavioural problems & $.169\left(^{*}\right)$ & 0.071 \\
Depression, anxiety & -.132 & $-.239\left(^{* *}\right)$ \\
\hline
\end{tabular}

** Correlation is significant at the 0.01 level (1-tailed).

* Correlation is significant at the 0.05 level (1-tailed).

tic behaviour was seen in 9 persons ( 8 males, 1 female) with profound intellectual disability. Psychotic episodes were diagnosed and treated in only one highly functioning person. Behavioural changes were common in adults with early stages of Alzheimer's disease.

The severity of intellectual disability correlated with language impairment and age $(p<0.01)$. Speech impairment had a negative correlation with the depression/anxiety score $(p<0.05)$. (Table 5.)

After adjustment for the effects of age and birth year and when partial correlations were used, the same correlations as described above emerged, with the exception of a correlation of the severity of intellectual disability with behavioural problems $(p<0.05)$. (Table 6.)

\section{Case descriptions}

The following five cases were selected to represent the behavioural and mental health issues seen in people with Down syndrome from childhood to adulthood.

\section{Case 1: Attention deficit hyperactivity disorder?}

Bill is a 5-year-old boy with Down syndrome, the second of two children of young parents. Bill is in a good physical condition in spite of his congenital heart defect and has no symptoms even in strenuous activities. Bill has food allergies to grains and milk. He has had recurrent respiratory infections and prolonged inflammation of the middle ear since the age of three. Bill sleeps well when healthy. He has excellent self-care skills for his age, and he even imitates household chores. Bill has walked since the age of two and run since the age of three. Bill is always active and climbs without fear. He has good receptive language abilities but speech production is limited to a few words. He uses signs in communication. Bill attends a day care centre with a personal assistant. $\mathrm{He}$ has a short attention span. His behaviour is hyperactive and impulsive. He accepts directions but needs continuous close surveillance for safety.

\section{Case 2: Depression, obsessive- compulsive disorder, self-injurious behaviour}

Paul is a 25-year-old man with Down syndrome, the youngest of the four children of elderly parents. Paul had frequent respiratory infections before heart surgery (closure of an arterial duct at the age of 7) and has had ear infections up till the present. He developed mild conductive hearing loss due to perforated eardrums. Speech production was very limited. Cognitive impairment was mild to moderate. Paul participated actively in certain household chores and sheltered work, being always very reliable and punctual in these activities. Paul has only a few permanent friends. He experienced a considerable rapid loss of weight, loss of appetite, loss of interest and impaired sleep with daytime tiredness and reduced activities at the age of 22 years. His grandfather had died 6 months earlier. He began to have increasing ritualistic and obsessive behaviours and even self-injurious behav- 
T. Määttä et al. • Mental health, behaviour and intellectual abilities of people with Down syndrome

iour and occasional aggressive outbursts. No somatic disease was detected in thorough evaluations at hospital. Antidepressant medication was started with an exceptionally slow response at a high dose (60 mg citalopram daily). Depression was relieved, but rituals and sleep disorder persisted even after 3 years of treatment.

\section{Case 3: Psychosis}

Helen is a 30 -year-old woman with trisomy-21, mild intellectual disabilities and good communication skills, including fluent speech. She has been on thyroxin treatment for hypothyroidism since 4 years of age. Her general health status is good. She has good skills in the activities of daily living. She lives with her elderly mother. During her mother's holiday two years ago Helen became extremely anxious and fearful. She could not sleep properly, stopped eating and became psychotic with delusions and visual hallucinations. She was hospitalised and treated with appropriate medication. Her symptoms subsided within a month, and she returned home with medication.

\section{Case 4: Self-injurious behaviour}

Anton is a 38 -year-old man with Down syndrome and severe intellectual disability. Anton participated in daily activities since childhood. His speech was limited to a few expressions but he could express his wishes by gestures and showing. Anton had recurrent acute ear infections until early adulthood. All remaining teeth were extracted because of advanced caries at age 22. Self-mutilation became a major problem at age 25 with no obvious reason. Anton hit and teased his ears and head, causing recurrent deep wounds, skin infections and finally permanent deformity of the ears. In order to enable healing of the ears, teasing was prevented by restraining his hands. Anton started kicking carers when they approached. Anton has now spent many years with his extremities and body restrained all the time so that he cannot injure himself or his carers. Anton's chronically inflamed gallbladder with stones was removed at age 33. All attempts to release him have so far failed. Anton seems to be content and calm when restrained. As soon as a limb is freed, he hits or kicks his carers or himself.

\section{Case 5: Depression, Alzheimer's disease}

Tom is a 51-year-old man with trisomy-21 and moderate to severe intellectual disability. Tom grew up with his mother and sister. Tom's depression started at age 20, and he has been treated with antidepressants since age 25 . Hypothyroidism was diagnosed at age 39. Cataracts were extracted at age 47 , and gallstone surgery was also done. Increasing forgetfulness, irritability, withdrawal, occasional aggressive outbursts and declining self-care skills have been observed during the past 5 years. Alzheimer's disease was diagnosed at the age of 49 years. Small hippocampal regions were detected in a brain MRI. Risperidone treatment at $0.5-1 \mathrm{mg}$ daily with a good response in behavioural symptoms was started 3 years ago. Epileptic seizures started two and half years ago, but no convulsions have occurred during sodium valproate medication. Further decline of skills was seen in repeated Adaptive Behaviour Scale assessments. Donepezil treatment at $5 \mathrm{mg}$ daily was started 2 years ago. Carers described a favourable response: better mood, increased activity and revival of interest. Tom still participates in daily activities, recognises familiar people and enjoys listening to songs. Speech and mobility are well preserved.

\section{Discussion}

The present study surveyed intellectual abilities, behaviour and mental health in an unselected populationbased series of people with Down syndrome. Behavioural symptoms occurring at any age after childhood were common and often severe. A large variety of physical diseases and behavioural symptoms occur in this population. The possibility of physical illnesses and sensory impairments should always be considered when behavioural change is evaluated.

Females showed milder degrees of intellectual disability, more developed speech and less challenging behaviour compared with males. People with mild to moderate intellectual disability and better speech are often able to express their feelings verbally, which may be helpful to adaptation.

Short attention span was repeatedly observed and described in the records of children. Attention deficit hyperactivity disorder was neither diagnosed nor medically treated, however. There is surprisingly little published literature on attention problems in people with Down syndrome, and no evidence-based recommendations for their treatment exist so far.

Depression was the main mental health problem seen in young adults in the present study, as it has also been in earlier studies (Myers \& Pueschel, 1991, Collacott et al., 1992). Depression had been recognised mainly in people with mild to moderate intellectual disabilities. The difficulty in diagnosing mental health problems in people with severe to profound intellectual disabilities is one possible explanation. Those with better cognitive abilities might be living with less support and experience stress.

Many researchers have discussed the possible link between depression and Alzheimer's disease. Depression and Alzheimer's disease are both common in people with Down syndrome. Adaptive behaviour decline often affects people with Down syndrome in their fifties. Burt et al., (1992) found the severity of depression to correlate with lower mental age, poorer memory and lower level of 
adaptive functioning in adults with Down syndrome but not in people with intellectual disabilities due to other causes. Their results suggest that dementia and depression are associated in Down syndrome.

Learning and adaptive behaviour are variably affected in all people with Down syndrome. Sensory impairments are also extremely common and may affect learning and cognitive development. Depression is a common treatable condition in people with Down syndrome. Age-related decline in adaptive behaviour has been established in adults with Down syndrome. In many cases, experimental treatment with antidepressants and cholinesterase inhibitors proved helpful even when the diagnosis of depression or Alzheimer's disease could not be confirmed.

The present study shows that mental health and behavioural problems, including attention deficit hyperactivity disorder, obsessive-compulsive disorder, self-injurious behaviour, depression and Alzheimer's disease, affect a considerable proportion of people with Down syndrome. Only a few treatments available to enhance health, learning and adaptation have been sufficiently evaluated and optimally implemented so far. Therefore, further studies are warranted on the therapeutic and preventive strategies applicable to behavioural problems in people with Down syndrome. Management of behavioural and of mental health problems should have a high priority in the available services because they will be beneficial not only to the individual served, but also to the family's wellbeing (McIntyre et al., 2002). Possible decline in adaptive abilities with advancing age needs to be considered in the support provision.

\section{Acknowledgements}

The study was supported by grants from the Finnish Cultural Foundation and the Rinnekoti Research Foundation.

\section{Correspondence}

Tuomo Määttä • Service Centre of Kuusanmäki, 87250

Kajaani, Finland • Tel: +358 $861562905 \bullet$ fax: +358 8

61562932,•e-mail:tuomo.maatta@kainuu.f

\section{References}

Burt, D.B., Loveland, K.A. \& Lewis, K.R. (1992).

Depression and the onset of dementia in adults with mental retardation. American Journal of Mental Retardation, 96(5), 502-11.

Chapman, R.S. \& Hesketh, L.J. (2000). Behavioral phenotype of individuals with Down syndrome. Mental Retardation and Developmental Disability Research Review, 6(2), 84-95.
Collacott, R.A., Cooper, S.A. \& McGrother, C. (1992). Differential rates of psychiatric disorders in adults with Down's syndrome compared with other mentally handicapped adults. British Journal of Psychiatry, 161, 671-4.

Collacott, R.A., Cooper, S.A., Branford, D. \& McGrother, C. (1998). Behaviour phenotype for Down's syndrome. British Journal of Psychiatry, 172, 85-9.

Cooper, S.A. \& Prasher, V.P. (1998). Maladaptive behaviours and symptoms of dementia in adults with Down's syndrome compared with adults with intellectual disability of other aetiologies. Journal of Intellectual Disability Research, 42 (Pt 4), 293-300.

Cosgrave, M.P., Tyrrell, J., McCarron, M., Gill, M. \& Lawlor, B.A. (1999). Determinants of aggression, and adaptive and maladaptive behaviour in older people with Down's syndrome with and without dementia. Journal of Intellectual Disability Research, 43(Pt 5), 393-9.

Dykens, E.M., Shah, B., Sagun, J., Beck, T. \& King, B.H. (2002). Maladaptive behaviour in children and adolescents with Down's syndrome. Journal of Intellectual Disability Research, 46(Pt 6), 484-92.

Evans, D.W. \& Gray, F.L. (2000). Compulsive-like behavior in individuals with Down syndrome: its relation to mental age level, adaptive and maladaptive behavior. Child Development, 71(2), 288-300.

Haveman, M.J., Maaskant, M.A., van Schrojenstein Lantman, H.M., Urlings, H.F. \& Kessels, A.G. (1994). Mental health problems in elderly people with and without Down's syndrome. Journal of Intellectual Disability Research, 38(Pt 3), 341-55.

Libb, J.W., Myers, G.J., Graham, E. \& Bell, B. (1983). Correlates of intelligence and adaptive behaviour in Down's syndrome. Journal of Mental Deficiency Research, 27(Pt 3), 205-10.

McCarthy, J. \& Boyd, J. (2001). Psychopathology and young people with Down's syndrome: childhood predictors and adult outcome of disorder. Journal of Intellectual Disability Research, 45(Pt 2), 99-105.

McIntyre, L.L., Blacher, J.M. \& Baker, B.L. (2002). Behaviour/mental health problems in young adults with intellectual disability: the impact on families. Journal of Intellectual Disability Research, 46(Pt 3), 239-249.

Myers, B.A. \& Pueschel, S.M. (1991). Psychiatric disorders in persons with Down syndrome. The Journal of Nervous and Mental Disease, 179(10), 609-13.

Myers, B.A., Pueschel, S.M. (1995). Major depression in a small group of adults with Down syndrome. Research of Developmental Disability, 16(4), 285-99. 
T. Määttä et al. • Mental health, behaviour and intellectual abilities of people with Down syndrome

Nagumo, N. (1994). [The nature of intelligence in adults with Down syndrome: IQ distribution and sex differences][Article in Japanese] Shinrigaku Kenkyu, 65(3), 240-5

Nelson, L.D., Orme, D., Osann, K. \& Lott, I.T. (2001). Neurological changes and emotional functioning in adults with Down Syndrome. Journal of Intellectual Disability Research, 45(Pt 5), 450-6.

Sharav, T., Collins, R. \& Shlomo, L. (1985). Effect of maternal education on prognosis of development in children with Down syndrome. Pediatrics, 76(3), 387-91.

World Health Organization (WHO) (1992). International Classification of Diseases - 10th revision (ICD10). World Health Organization, Geneva. 